\title{
GBIF Benin's Data Portal
}

\author{
Marie-Elise Lecoq $^{\ddagger}$, Anne-Sophie Archambeau ${ }^{\ddagger}$, Fabien Cavière ${ }^{\ddagger}$, Kourouma Kouras, Sophie \\ Pamerlon ${ }^{\ddagger}$, Jean C. Ganglo§ \\ ‡ UMS PatriNat - GBIF France, Paris, France \\ $\S$ Laboratoire des Sciences Forestières, Faculté des Sciences Agronomiques, Université d'Abomey-Calavi, Abomey-Calavi, \\ Benin
}

Corresponding author: Marie-Elise Lecoq (melecoq@gbif.fr)

Received: 16 Apr 2018| Published: 22 May 2018

Citation: Lecoq M, Archambeau A, Cavière F, Koura K, Pamerlon S, Ganglo J (2018) GBIF Benin's Data Portal.

Biodiversity Information Science and Standards 2: e25890. https://doi.org/10.3897/biss.2.25890

\begin{abstract}
GBIF Benin, hosted at the University of Abomey-Calavi, has published more than 338,000 occurrence records in 87 datasets and checklists. It has been a Global Biodiversity Information Facility (GBIF) node since 2004 and is a leader in several projects from the Biodiversity Information for Development (BID) programme.

GBIF facilitates collaboration between nodes at different levels through its Capacity Enhancement Support Programme (CESP) [https://www.gbif.org/programme/82219/ capacity-enhancement-support-programme]. One of the actions included in the CESP guidelines is called 'Mentoring activities'. Its main goal is the transfer of knowledge between partners such as information, technologies, experience, and best practices.
\end{abstract}

Sharing architecture and development is the key solution to solve some technical challenges or impediments (hosting, staff turnover, etc.) that GBIF nodes could face. The Atlas of Living Australia (ALA) team developed a functionality called 'data hub'. It gives the possibility to create a standalone website with a dedicated occurrence search engine that seeks among a range of data (e.g. specific genus, geographic area).

In 2017, GBIF Benin and GBIF France wanted to strengthen their partnership and started a CESP project. One of the core objectives of this project is the creation of the Atlas of Living Benin using ALA modules. GBIF France developers, with the help of the GBIF Benin team, are in the process of configuring a data hub that will give access to Beninese data only, 
while at the same time Atlas of Living France will give access to French data only. Both data portals will use the same back end, therefore the same databases. Benin is the first African GBIF node to implement this kind of infrastructure.

On this poster, we will present the Atlas of Living Benin specific architecture and how we have managed to distinguish data coming from Benin and coming from France.

\section{Keywords}

GBIF Benin, GBIF France, ALA, CESP

\section{Presenting author}

Marie-Elise Lecoq

Fabien Cavière 